Case

Reports

Karen B. James, MD

L. Kathleen Centorbi, RN Roberto Novoa, MD
Key words: Aortic valve; aortic valve insufficiency; aortic valve, quadricuspid aortic valve stenosis; heart defects, congenital; regurgitation, aortic valve

From: The Department of Cardiology (Dr. James and Ms. Centorbi) and the Department of Cardiothoracic Surgery (Dr. Novoa), The Cleveland Clinic Foundation, Cleveland, Ohio

Address for reprints: Karen B. James, MD, Department of Cardiology, Desk F-15, The Cleveland Clinic Foundation, 9500 Euclid Avenue, Cleveland, $\mathrm{OH} 44195$

\section{Quadricuspid Aortic Valve}

\author{
Case Report and Review of the Literature
}

Quadricuspid aortic valve is a rare congenital anomaly that may be found unexpectedly at surgery or diagnosed preoperatively by means of echocardiography or aortography. The most common hemodynamic abnormality associated with this anomaly is aortic insufficiency.

We describe a representative case involving a 62-year-old man with severe aortic insufficiency and mild aortic stenosis. At operation, the aortic valve was found to have 4 cusps. The valve was replaced with a mechanical prosthesis. The patient was released 7 days after operation and was clinically well at 6-month follow-up. (Texas Heart Institute Journal 1991;18:141-3)

$\mathbf{Q}$ uadricuspid aortic valve, a rare variant of semilunar valve anatomy, is often an unexpected finding at surgery. We present a recent case of this anomaly and a current review of the literature.

\section{Case Report}

A 62-year-old man presented for evaluation of a diastolic heart murmur. His symptoms included mild exertional dyspnea of 1 year's duration and occasional palpitations. Physical examination revealed a blood pressure of $140 / 70 \mathrm{mmHg}$ and bounding pulses. A grade $4 / 6$ diastolic decrescendo murmur was loudest at the 2 nd right intercostal space. There was also a grade $3 / 6$ midsystolic murmur, which was loudest at the upper right sternal border. The electrocardiogram showed normal sinus rhythm and left ventricular hypertrophy. Chest radiography disclosed mild cardiomegaly with a cardiothoracic ratio of $17.5 / 33$. Calcification was seen in the aorta.

Doppler echocardiography revealed severe (4+) aortic insufficiency. The mean transvalvular gradient was $55 \mathrm{mmHg}$, with a calculated valve area of $1.26 \mathrm{~cm}^{2}$. The markedly dilated left ventricle had an end-diastolic dimension of $78 \mathrm{~mm}$ and an end-systolic dimension of $48 \mathrm{~mm}$; it exhibited overall hyperdynamic contractility. During cardiac catheterization, aortography confirmed the presence of severe (4+) aortic insufficiency and revealed only trivial coronary artery disease. Neither 2dimensional echocardiography nor aortography showed the aortic valve morphology. On the basis of the patient's severe aortic insufficiency, enlarged heart, and other symptoms, we recommended aortic valve replacement.

The patient subsequently underwent implantation of a St. Jude Medical mechanical aortic valve. The native valve was found to be quadricuspid with 2 equal large cusps and 2 equal smaller cusps (Fig. 1). The valve leaflets were severely calcified, and the commissures were slightly fused. Mild myxoid degeneration was also seen. There was no evidence of endocarditis or rheumatic valvulitis. The patient was released from the hospital on the 7th postoperative day. At 6-month follow-up, the patient was clinically well; the preoperative exertional dyspnea, palpitations, and murmurs were all resolved.

\section{Discussion}

The 1st quadricuspid aortic valve was described by Balington ${ }^{1}$ in 1862 . Since that time, 52 additional cases have been reported in the literature. ${ }^{2.3}$ The incidence, which ranges from $0.008 \%$ to $0.033 \%,{ }^{5}$ is nearly equal in men and women, although some authors ${ }^{5.6}$ have described a male predilection. Early reports were based on 


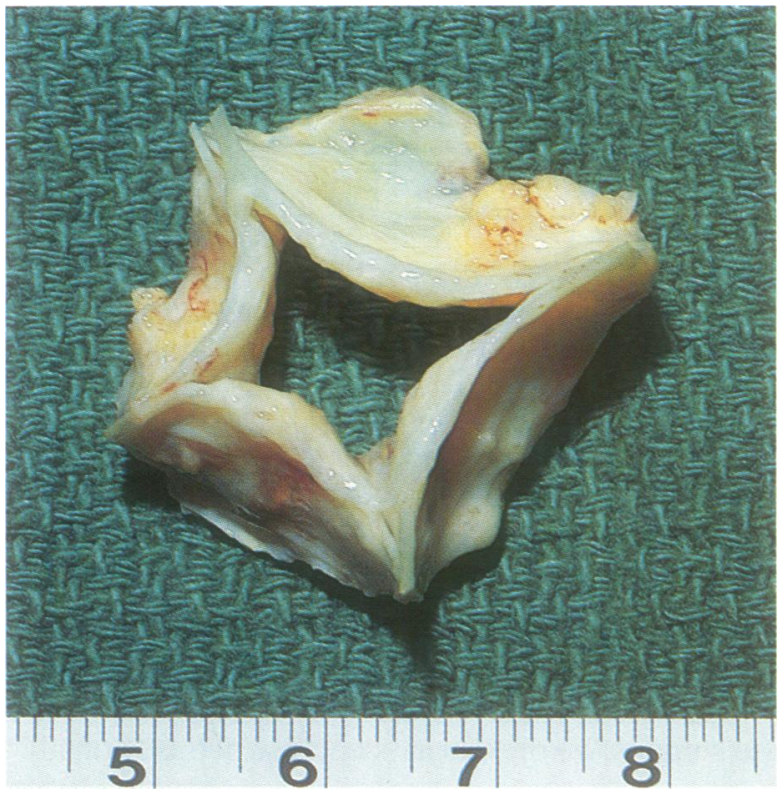

Fig. 1 Quadricuspid aortic valve, with severely calcified leaflets and slightly fused commissures.

autopsy or surgical findings, often unexpected; more recently, aortography and 2-dimensional echocardiography have allowed earlier diagnosis of this entity. ${ }^{7-9}$ Because quadricuspid aortic valve may be overlooked at autopsy unless it is specifically sought, its incidence may be underestimated. On the other hand, if the valve has been excised in small pieces, the number of cusps may be assessed inaccurately, thereby causing the incidence of quadricuspid aortic valve to be overestimated.

Embryologically, the aortic valve is formed when the truncus arteriosus partitions into the aortic and pulmonic valves. In the walls of the aortic and pulmonic trunks, 3 small pads of connective tissue develop to form the primordia of the semilunar cusps. When deviations from this symmetric arrangement occur, the semilunar valves may have 2,4 , or even 5 cusps. ${ }^{10}$

The hemodynamic status of a quadricuspid aortic valve may be related to its morphology. Hurwitz and Roberts ${ }^{5}$ have classified such valves into 7 types, depending on the size and degree of equality of the 4 cusps (Table I). A quadricuspid aortic valve will not necessarily cause hemodynamic compromise. Nevertheless, approximately $44 \% 5.9$ of these valves will exhibit a hemodynamic abnormality, aortic insufficiency being the most common finding. Although aortic stenosis rarely has been reported, ${ }^{5,11,12}$ our patient did exhibit mild-to-moderate aortic stenosis with a valve area of $1.26 \mathrm{~cm}^{2}$, as stated earlier.

At least 1 report concerning endocarditis in a quadricuspid aortic valve has been published..$^{13}$ The risk of endocarditis in patients with such valves has
TABLE I. Quadricuspid Aortic Valve Types, Based on Cusp Size and Degree of Cusp Equality

\author{
1) 3 equal large cusps, 1 smaller cusp \\ (most common type) \\ 2) 4 equal cusps \\ 3) 2 equal large cusps, 2 equal smaller cusps \\ 4) 1 large cusp, 2 intermediate-sized cusps, 1 small cusp \\ 5) 3 equal small cusps, 1 larger cusp \\ 6) 2 equal large cusps, 2 unequal smaller cusps \\ 7) 4 unequal cusps
}

(Adapted from Hurwitz LE, Roberts WC. ${ }^{5}$ )

been debated. Some experts ${ }^{12}$ believe that the risk is low in valves with 4 equal cusps, because of the lack of asymmetry or flow disturbance. In valves with unequal cusps, however, uneven distribution of stress and incomplete juxtaposition during diastole may lead to progressive aortic insufficiency and gradual deterioration over the years, generating speculation that patients who have valves with unequal cusps may be at higher risk for endocarditis. This deterioration may also explain why quadricuspid aortic valves usually become manifest later in life.

Quadricuspid aortic valve is not generally associated with other congenital cardiac defects. Nonetheless, occasional reports of association with patent ductus arteriosus, ${ }^{4}$ subvalvular aortic stenosis, ${ }^{14}$ a ventricular septal defect, ${ }^{6}$ or a congenitally deficient mitral leaflet ${ }^{11}$ have appeared in the literature. Concomitant coronary anomalies, including single coronary artery and displacement of the right or left coronary ostium, have also been reported. ${ }^{15-17}$ In 1 case, a quadricuspid aortic valve cusp caused domelike occlusion of the left coronary ostium, resulting in sudden death. ${ }^{18}$

For severe valvular malfunction (usually insufficiency), aortic valve replacement is generally the treatment of choice, as it was in our patient. At this stage, the valve is usually calcified and impossible to repair. At an early stage, however, this anomaly should be no more technically difficult to repair than a prolapsing aortic valve. ${ }^{19}$ Iglesias and associates ${ }^{14}$ converted a quadricuspid aortic valve into a tricuspid valve by anastomosing the commissures of the right coronary and supranumerary cusps, thereby restoring normal coaptation. Such a conservative operative approach may become more common as increased physician awareness and improved diagnostic techniques allow earlier detection of quadricuspid aortic valves. 


\section{References}

1. Balington J. London Medical Gazette, July 1862.

2. Fischler D, Fitzmaurice M, Ratliff NB Jr. Quadricuspid aortic valve. Am J Cardiovasc Pathol 1990;3:91-4.

3. Coltharp WH, Warren ET, Heath BJ. Quadricuspid aortic valve with centrally fenestrated leaflets causing aortic insufficiency. Tex Heart Inst J 1988;15:187-8.

4. Simonds JP. Congenital malformation of aortic and pulmonary valves. Am J Med Sci 1923;166:584-95.

5. Hurwitz LE, Roberts WC. Quadricuspid semilunar valve. Am J Cardiol 1973;31:623-6.

6. Fernicola DJ, Mann JM, Roberts WC. Congenitally quadricuspid aortic valve: analysis of six necropsy patients. Am J Cardiol 1989;63:136-8.

7. Nalbantgil I, Cagatay G. Quadricuspid aortic valve [letter]. Chest 1975;67:623-4.

8. Brandenburg RO Jr, Tajik AJ, Edwards WD, Reeder GS, Shub C, Seward JB. Accuracy of 2-dimensional echocardiographic diagnosis of congenitally bicuspid aortic valve: echocardiographic-anatomic correlation in 115 patients. Am J Cardiol 1983;51:1469-73.

9. Herman RL, Cohen IS, Glaser K, Newcomb EW III. Diagnosis of incompetent quadricuspid aortic valve by two-dimensional echocardiography. Am J Cardiol 1984;53:972.

10. McRonald RE, Dean DC. Congenital quadricuspid aortic valve. Am J Cardiol 1966;18:761-3.

11. Davia JE, Fenoglio JJ, DeCastro CM, McAllister HA Jr, Cheitlin MD. Quadricuspid semilunar valves. Chest 1977;72:186-9.
12. Feldman BJ, Khandheria BK, Warnes CA, Seward JB, Taylor $\mathrm{CL}$, Tajik AJ. Incidence, description and functional assessment of isolated quadricuspid aortic valves. Am J Cardiol 1990;65:937-8.

13. Matsukawa T, Yoshii S, Hashimoto R, Muto S, Suzuki S, Ueno A. Quadricuspid aortic valve perforation resulting from bacterial endocarditis: 2-D echo- and angiographic diagnosis and its surgical treatment. Jpn Circ J 1988;52:437-40.

14. Iglesias A, Oliver J, Muñoz JE, Nuñez L. Quadricuspid aortic valve associated with fibromuscular subaortic stenosis and aortic regurgitation treated by conservative surgery. Chest 1981;80:327-8.

15. Kim HS, McBride RA, Titus JL. Quadricuspid aortic valve and single coronary ostium. Arch Pathol Lab Med 1988;112: 842-4.

16. Lanzillo G, Breccia PA, Intonti F. Congenital quadricuspid aortic valve with displacement of the right coronary orifice. Scand J Thorac Cardiovasc Surg 1981;15:149-51.

17. Robicsek F, Sanger PW, Daugherty HK, Montgomery CC. Congenital quadricuspid aortic valve with displacement of the left coronary orifice. Collected Works Cardiopulmonary Diseases 1968;14:87-90.

18. Kurosawa H, Wagenaar SS, Becker AE. Sudden death in a youth: a case of quadricuspid aortic valve with isolation of origin of left coronary artery. Br Heart J 1981;46:211-5.

19. Cosgrove DM, Rosenkranz ER, Hendren WG, et al. Valvuloplasty for aortic insufficiency. J Thorac Cardiovasc Surg [in press]. 